\title{
A gene-based risk score model for predicting recurrence-free survival in patients with hepatocellular carcinoma
}

\author{
Wenhua Wang ${ }^{1,2}$, Lingchen Wang ${ }^{1,2}$, Xinsheng Xie ${ }^{3}$, Yehong Yan ${ }^{4}$, Yue $\mathrm{Li}^{1,2}$ and Quqin $\mathrm{Lu}^{1,2^{*}}$ (D)
}

\begin{abstract}
Background: Hepatocellular carcinoma (HCC) remains the most frequent liver cancer, accounting for approximately $90 \%$ of primary liver cancers worldwide. The recurrence-free survival (RFS) of HCC patients is a critical factor in devising a personal treatment plan. Thus, it is necessary to accurately forecast the prognosis of HCC patients in clinical practice.

Methods: Using The Cancer Genome Atlas (TCGA) dataset, we identified genes associated with RFS. A robust likelihood-based survival modeling approach was used to select the best genes for the prognostic model. Then, the GSE76427 dataset was used to evaluate the prognostic model's effectiveness.

Results: We identified 1331 differentially expressed genes associated with RFS. Seven of these genes were selected to generate the prognostic model. The validation in both the TCGA cohort and GEO cohort demonstrated that the 7-gene prognostic model can predict the RFS of HCC patients. Meanwhile, the results of the multivariate Cox regression analysis showed that the 7-gene risk score model could function as an independent prognostic factor. In addition, according to the time-dependent ROC curve, the 7-gene risk score model performed better in predicting the RFS of the training set and the external validation dataset than the classical TNM staging and BCLC. Furthermore, these seven genes were found to be related to the occurrence and development of liver cancer by exploring three other databases.
\end{abstract}

Conclusion: Our study identified a seven-gene signature for HCC RFS prediction that can be used as a novel and convenient prognostic tool. These seven genes might be potential target genes for metabolic therapy and the treatment of HCC.

Keywords: TCGA, Hepatocellular carcinoma, Recurrence-free survival, Risk score, Prognostic model

\footnotetext{
* Correspondence: quqinlu@ncu.edu.cn

${ }^{1}$ Jiangxi Provincial Key Laboratory of Preventive Medicine, Nanchang University, Nanchang 330006, Jiangxi, China

${ }^{2}$ Department of Biostatistics and Epidemiology, School of Public Health, Nanchang University, Nanchang 330006, Jiangxi, China

Full list of author information is available at the end of the article
}

(c) The Author(s). 2021 Open Access This article is licensed under a Creative Commons Attribution 4.0 International License, which permits use, sharing, adaptation, distribution and reproduction in any medium or format, as long as you give appropriate credit to the original author(s) and the source, provide a link to the Creative Commons licence, and indicate if changes were made. The images or other third party material in this article are included in the article's Creative Commons licence, unless indicated otherwise in a credit line to the material. If material is not included in the article's Creative Commons licence and your intended use is not permitted by statutory regulation or exceeds the permitted use, you will need to obtain permission directly from the copyright holder. To view a copy of this licence, visit http://creativecommons.org/licenses/by/4.0/ The Creative Commons Public Domain Dedication waiver (http://creativecommons.org/publicdomain/zero/1.0/) applies to the data made available in this article, unless otherwise stated in a credit line to the data. 


\section{Background}

In 2018, liver cancer remained among the top six prevalent carcinomas. There were 841,080 new patients, and 781,631 patients died of liver cancer according to the Global Cancer Statistics [1, 2]. Hepatocellular carcinoma (HCC) is the most frequent liver cancer, accounting for approximately $90 \%$ of primary liver cancers [3]. Currently, Hepatectomy and Radiofrequency ablation are the main two ways to treat HCC $[4,5]$. Despite the continuous development of medical technology, the outcome of many patients who receive treatment and the prognosis of liver cancer remain poor with a 2-year recurrence rate of $76.9 \%$ [6-8]. And many studies have shown that $\mathrm{HCC}$ is the most difficult to cure cancer, and because of this, HCC has been described as a "chemoresistant" tumor [9]. Because of this, the prognosis of HCC is poor. The recurrence-free survival (RFS) of HCC patients is a critical factor in devising a personal treatment plan [10]. Thus, it is necessary to accurately forecast HCC patients' prognosis to improve the prognosis of HCC. Most previous studies constructed prognostic models using the Tumor-Node-Metastasis (TNM)
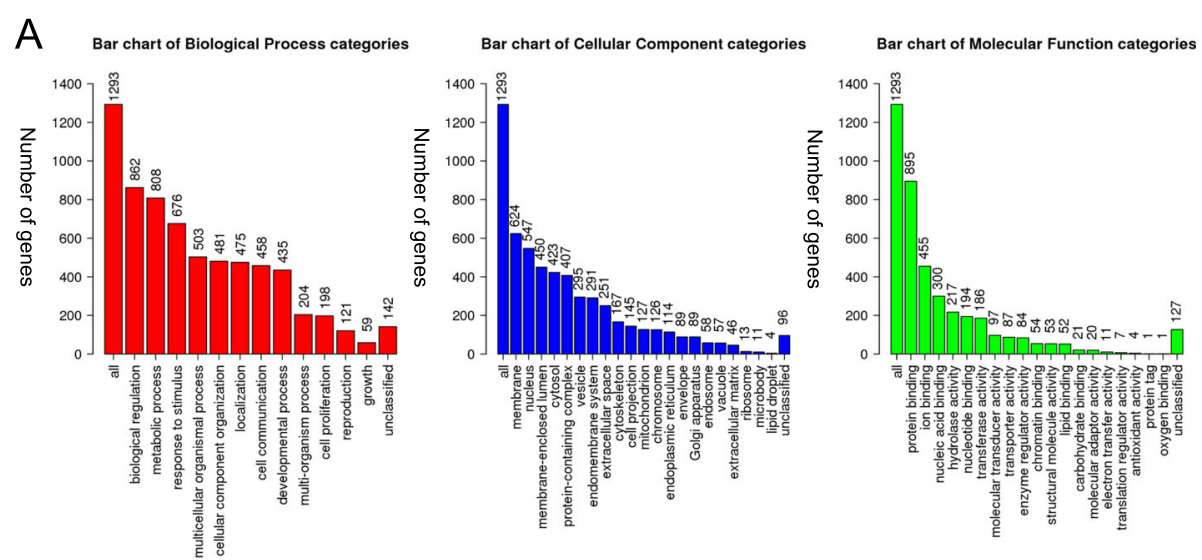

B

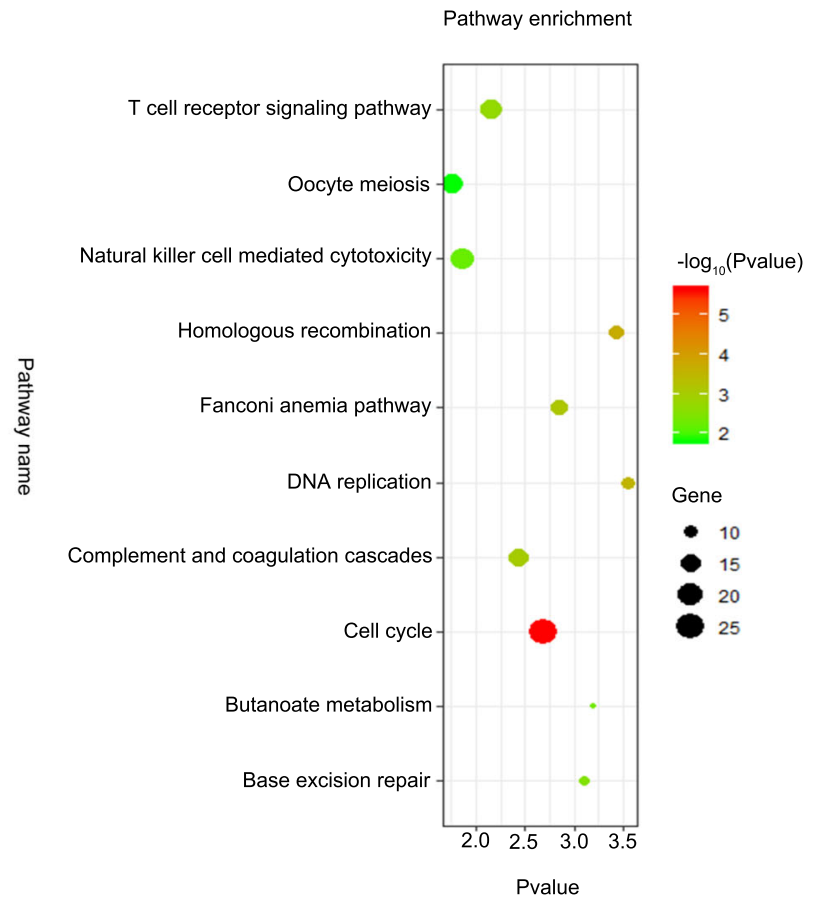

Fig. 1 GO functional and KEGG pathway analyses. a Summary of the differentially expressed genes and GO pathway enrichment. Red, blue, and green bars represent the biological process, cellular component, and molecular function categories, respectively. The height of the bar represents the number of differentially expressed genes observed in each category. $\mathbf{b}$ The top 10 pathways of genes associated with RFS 
staging system to assess the prognosis of HCC patients [11]. However, the TNM staging system does not predict the prognosis of HCC. Therefore, it is important to develop a reliable tool for clinicians to predict the prognosis of patients with HCC.

Given the remarkable advances in high-throughput technologies, the development of The Cancer Genome Atlas (TCGA) (https://portal.gdc.cancer.gov/) and the intergovernmental Gene Expression Omnibus (GEO) (https://www.ncbi.nlm.nih.gov/gds) database provides an abundance of high-quality information regarding HCC [12]. Hence, it is urgent to develop methods to identify reliable therapeutic gene targets that could enable earlier prognostic evaluation and better therapeutic strategies [13]. Therefore, we considered whether we could build a gene-based risk score model [14]. Our goal was to generate simple and effective prognostic tools based on several genes and other factors that may affect RFS $[13,15]$. Using the TCGA dataset, we selected 7 genes by robust likelihood-based survival modeling and built a risk score system [16, 17]. We used an independent dataset (GSE76427) to validate the effectiveness of the risk score system and demonstrate that its clinical value in predicting RFS in HCC patients is better than that of the TNM staging system.

\section{Methods}

\section{Data collection and survival analyses}

First, we downloaded gene expression profiles and clinical information from The Cancer Genome Atlas-liver hepatocellular carcinoma (TCGA-LIHC) dataset, which included 334 HCC samples [18]. We used GSE76427, which contained the gene expression and clinical information of 115 HCC samples, as the validation group. The samples in TCGA-LIHC and GSE76427 that met the following inclusion criteria were included in this study: all samples had mRNA sequencing data and clinical information related to RFS [19].

\section{Identification of genes associated with RFS}

The raw count data were normalized with a $\log (\mathrm{a}+1)$ transformation. Then, using the "survfit" function in the "survival" package, we plotted Kaplan-Meier curves for the high and low expression groups of each gene. A log rank test with a $p$-value less than 0.05 was considered statistically significant $[20]$.

Enrichment analysis of GO functions and KEGG pathways For the selected genes, we used WebGestalt (http:// bioinfo.vanderbilt.edu/webgestalt) based on Gene Ontology (GO) functions and the Kyoto Encyclopedia of Genes and Genomes (KEGG) to understand the biological significance of the identified genes [21].

\section{Identification of the best genes for modeling}

A robust likelihood-based survival approach was used to identify the best genes for modeling after determining the genes associated with RFS [22]. We used the "rbsurv" package in $\mathrm{R}$ to complete this modeling process.

\section{Construction and validation of the risk score system}

A multivariate Cox regression analysis and "rbsurv" analysis were performed to identify the genes related to RFS and construct the prognostic gene signature. The "survivalROC" package in $\mathrm{R}$ was used to investigate the timedependent prognostic value. The optimal cut-off values based on ROC curves were obtained to classify the patients into low-risk groups and high-risk groups. A calibration curve and the concordance index (C-index) were used to evaluate the risk score system.

\section{External validation of the risk score system}

We calculated the risk score in the GSE76427 dataset. Then, the AUCs of the 12-month, 15-month, and 18month RFS and Kaplan-Meier curves were used to verify the risk score system. A calibration curve was used to validate the risk score system. In addition, the prognosis-related genes included in the risk score system were verified at the protein level by using The Human Protein Atlas database. The CBioPortal for cancer genomics was used to study genetic alterations in the risk score system [23].

\section{Statistical analysis}

The statistical tests were performed using $\mathrm{R}$ software and SPSS. Univariate and multivariate Cox regression analyses were performed using a forward stepwise procedure. A $p$-value less than 0.05 was considered statistically significant [23].

Table 1 The best genes predicting recurrence-free survival of hepatocellular carcinoma patients

\begin{tabular}{llll}
\hline Gene symbol & nloglik & AIC & Select \\
\hline TTK & 808.79 & 1619.59 & $*$ \\
C16orf105 & 797.58 & 1599.16 & $*$ \\
PPAT & 791.22 & 1588.43 & $*$ \\
CD3EAP & 788.83 & 1585.66 & $*$ \\
SLCO2A1 & 787.91 & 1585.83 & $*$ \\
ACAT1 & 786.25 & 1584.50 & $*$ \\
GAS2L3 & 784.91 & 1583.83 & $*$ \\
SH2D5 & 784.84 & 1585.68 & \\
ATP8A2 & 784.75 & 1587.50 & \\
PABPC5 & 784.74 & 1589.49 & \\
\hline
\end{tabular}

${ }^{*}$ Gene selected for the risk score 

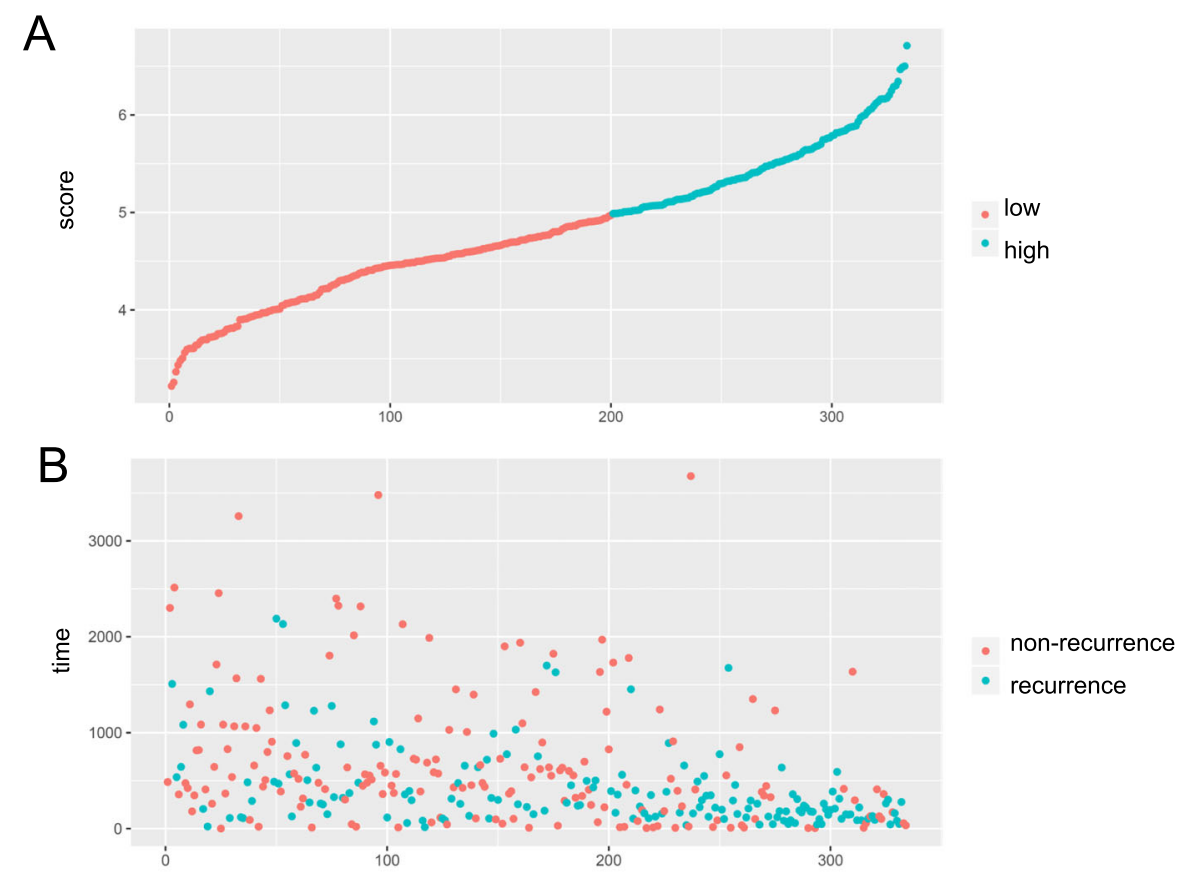

C
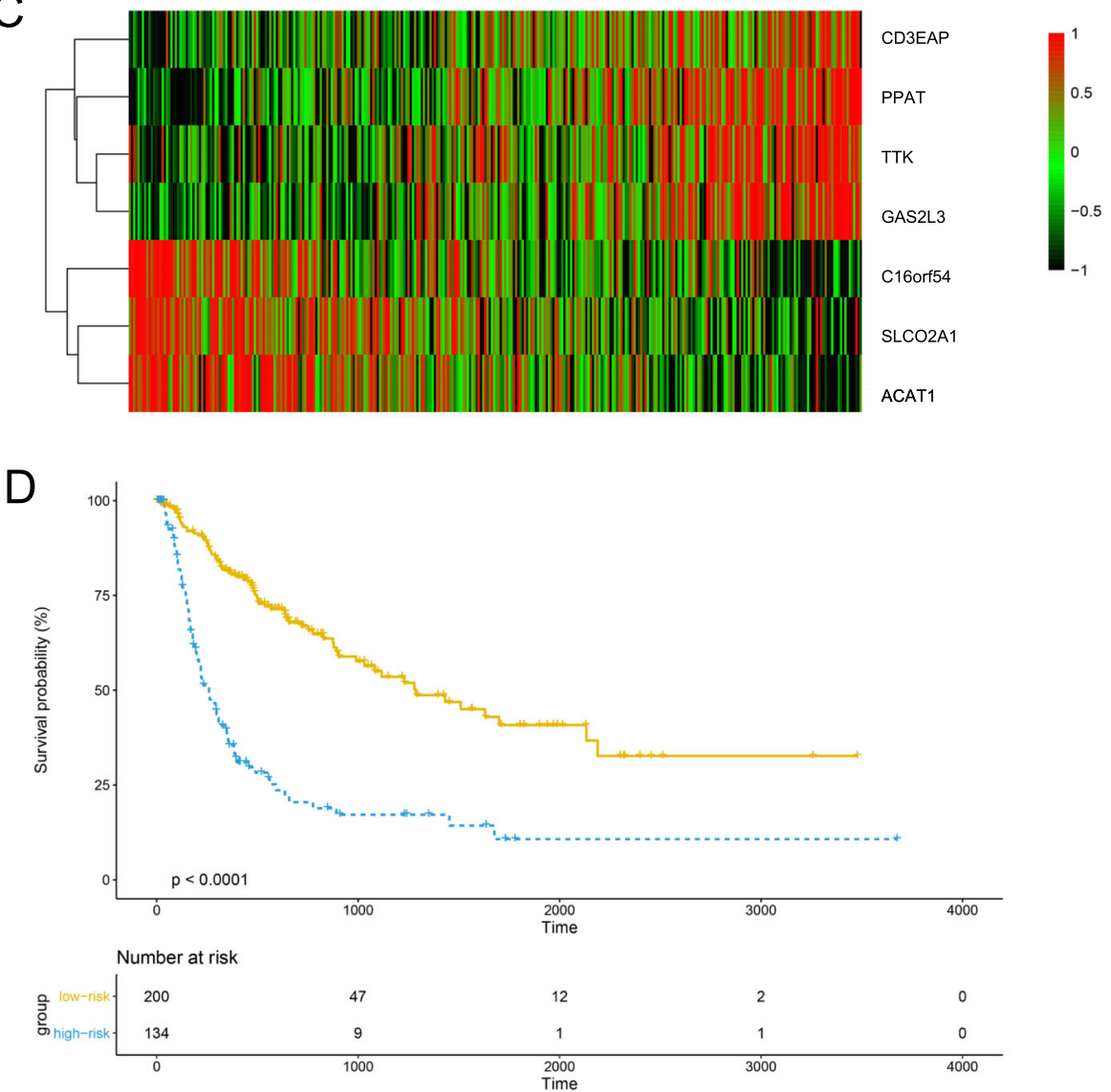

group - low-risk - - he high-risk

Fig. 2 Analysis of the seven-gene signature of HCC in TCGA dataset. a Risk score of each patient; $\mathbf{b}$ The RFS time and RFS status of the HCC patients; $\mathbf{c}$ the expression levels of TTK, C16orf105, PPAT, CD3EAP, SLCO2A1, ACAT1 and GAS2L3 in the signature; Kaplan-Meier analysis of the TCGA dataset; $\mathbf{d}$ The Kaplan-Meier curve for the risk score model in TCGA dataset 

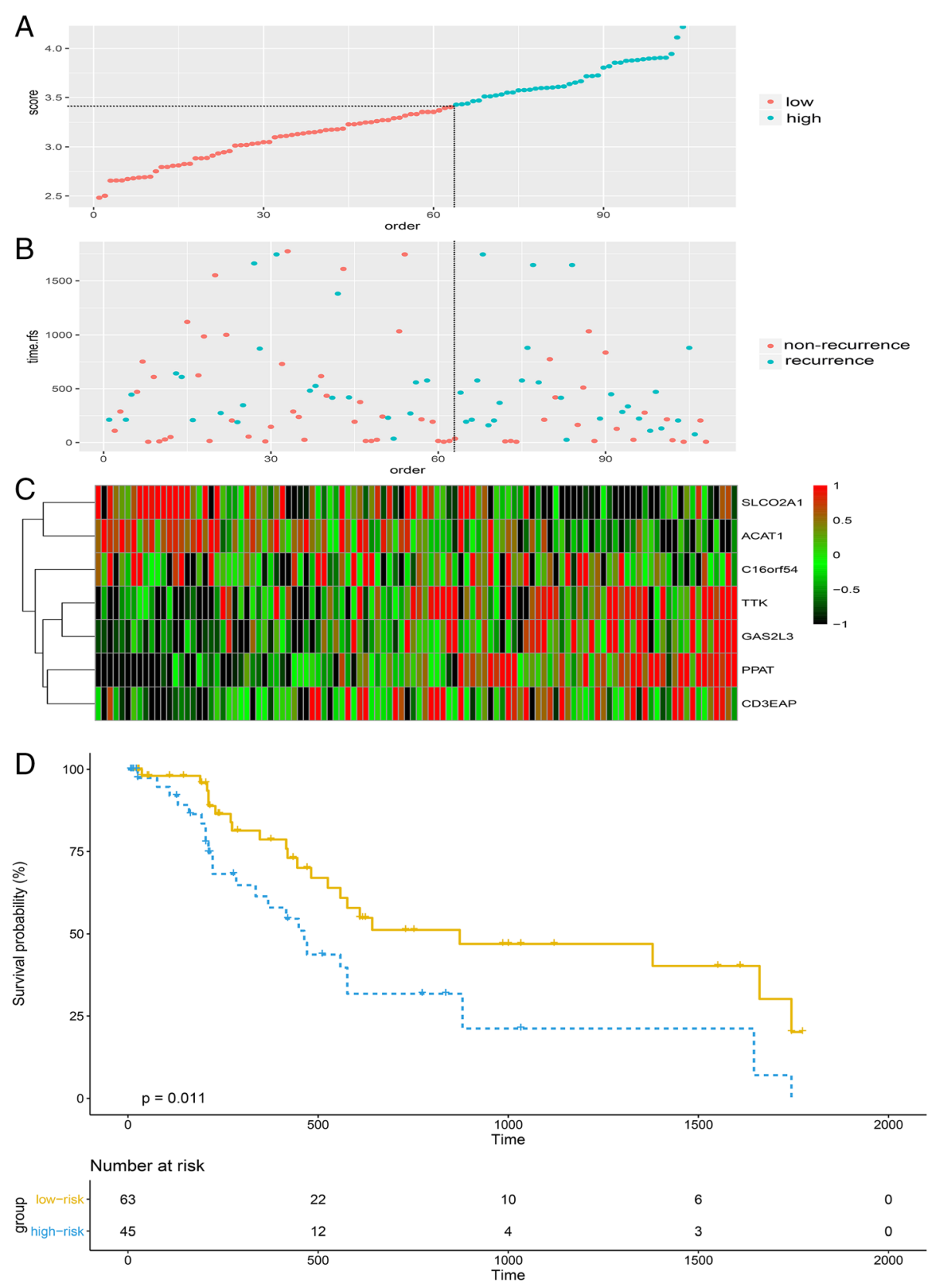

group + low-risk -tw high-risk

Fig. 3 Analysis of the seven-gene signature of HCC in GEO dataset. a risk score of each patient; $\mathbf{b}$ The RFS time and RFS status of the HCC patients; c The expression levels of TTK, C16orf105, PPAT, CD3EAP, SLCO2A1, ACAT1 and GAS2L3 in the signature; Kaplan-Meier analysis of the GSE76427 dataset; $\mathbf{d}$ The Kaplan-Meier curve for the risk score model in GEO dataset

\section{Results}

\section{Acquisition of the gene expression and clinical data} We downloaded the TCGA-LIHC dataset from The Cancer Genome Atlas (http://portal.gdc.cancer.gov/). The TCGA-LIHC dataset included 334 samples, 308 patients received hepatectomy, and the remaining 26 patients received radiofrequency ablation, and all samples included data regarding the RFS time and censoring status. The
GSE76427 dataset was downloaded from the Gene Expression Omnibus database (http://www.ncbi.nlm.nih.gov/ gov/). The GSE76427 dataset included 115 samples from HCC patients, but 7 patients had missing information regarding the RFS time and censoring status. Thus, 108 samples were included in this study, all 115 patients received hepatectomy. The median RFS times in the TCGA and GSE76427 series were 390 and 252 days, respectively, 
and the two datasets contained clinical information, such as gender, age, and the TNM stage.

\section{Genes associated with RFS}

We used the "survfit" function in the "survival" package and found 1331 genes associated with RFS. Then, to explore the genetic biological implications, we analyzed the 1331 genes through Gene Ontology (GO) functional and Kyoto Encyclopedia of Genes and Genomes (KEGG) pathway analyses. As shown in Fig. 1, in the KEGG analysis, we found that these genes are enriched in signaling pathways, such as the cell cycle, homologous recombination, DNA replication, the Fanconi anemia pathway, complement and coagulation cascades, and the $\mathrm{T}$ cell receptor signaling pathway.

Table 2 Characteristics of HCC patients in TCGA-LIHC dataset

\begin{tabular}{|c|c|c|c|c|c|c|c|c|c|c|c|}
\hline \multirow{3}{*}{ Variables Score } & \multicolumn{2}{|c|}{ 7-gene signature } & \multirow{3}{*}{$\begin{array}{l}\text { The chi- } \\
\text { square test } \\
p \text { value }\end{array}$} & \multicolumn{2}{|c|}{$\begin{array}{l}\text { Univariate } \\
\text { cox } \\
\text { regression }\end{array}$} & \multirow{3}{*}{\multicolumn{6}{|c|}{$\begin{array}{l}\text { a cut-off of } 4.9798 \text { for the risk score. Furthermore, the } \\
\text { survival curve revealed that the RFS in the high-risk } \\
\text { group was significantly poorer than that in the low-risk } \\
\text { group }(p<0.0001 \text {; Fig. } 2) \text {. }\end{array}$}} \\
\hline & $\begin{array}{l}\text { Low-risk } \\
(200)\end{array}$ & $\begin{array}{l}\text { High-risk } \\
\text { (134) }\end{array}$ & & HR & $\begin{array}{l}p \text { value } \\
<0.001\end{array}$ & & & & & & \\
\hline & & & & \multicolumn{2}{|c|}{3.607} & & & & & & \\
\hline \multicolumn{3}{|l|}{ Gender } & \multirow[t]{3}{*}{0.330} & \multirow[t]{3}{*}{0.975} & \multirow[t]{3}{*}{0.879} & \multirow{4}{*}{\multicolumn{6}{|c|}{$\begin{array}{l}\text { Validation of the prognostic model in GSE76427 } \\
\text { We validated the risk score system in the GSE76427 co- } \\
\text { hort. In total, } 108 \text { patients were divided into two groups } \\
\text { ( } 45 \text { high-risk patients and } 63 \text { low-risk patients) using a }\end{array}$}} \\
\hline Male & 140 & 87 & & & & & & & & & \\
\hline female & 60 & 47 & & & & & & & & & \\
\hline Age (years) & & & \multirow[t]{3}{*}{0.785} & \multirow[t]{3}{*}{1.048} & \multirow[t]{3}{*}{0.769} & & & & & & \\
\hline$<60$ & 91 & 63 & & & & & & & & & \\
\hline$\geq 60$ & 109 & 71 & & & & \multicolumn{6}{|c|}{ Table 3 Characteristics of HCC patients in GSE 76427 dataset } \\
\hline \multicolumn{3}{|l|}{$\mathrm{BMI}\left(\mathrm{kg} / \mathrm{m}^{2}\right)$} & \multirow[t]{3}{*}{0.061} & \multirow[t]{3}{*}{0.900} & \multirow[t]{3}{*}{0.509} & \multirow{4}{*}{ Variables Score } & \multirow{2}{*}{\multicolumn{2}{|c|}{ 7-gene signature }} & \multirow{4}{*}{$\begin{array}{l}\text { The chi- } \\
\text { square test } \\
p \text { value }\end{array}$} & \multirow{3}{*}{\multicolumn{2}{|c|}{$\begin{array}{l}\text { Univariate } \\
\text { cox } \\
\text { regression } \\
\end{array}$}} \\
\hline$<25$ & 91 & 75 & & & & & & & & & \\
\hline$\geq 25$ & 109 & 59 & & & & & & & & & \\
\hline TNM & & & $<0.001$ & 1.680 & $<0.001$ & & $\begin{array}{l}\text { Low- } \\
\text { risk }(63)\end{array}$ & $\begin{array}{l}\text { High- } \\
\text { risk (45) }\end{array}$ & & $\begin{array}{l}\mathrm{HR} \\
2.047\end{array}$ & $\begin{array}{l}p \text { value } \\
0.014\end{array}$ \\
\hline 1 & 123 & 44 & & & & gender & & & 0.374 & 0.609 & 0.208 \\
\hline$\|$ & 44 & 39 & & & & Male & 11 & 11 & & & \\
\hline III & 31 & 50 & & & & female & 52 & 34 & & & \\
\hline IV & 2 & 1 & & & & Age (years) & & & 0.161 & 1.048 & 0.769 \\
\hline Grade & & & 0.001 & 1.112 & 0.515 & $<60$ & 21 & 21 & & & \\
\hline $1+2$ & 139 & 68 & & & & $\geq 60$ & 42 & 24 & & & \\
\hline $3+4$ & 61 & 64 & & & & TNM & & & 0.877 & 1.267 & 0.191 \\
\hline NA & 0 & 2 & & & & I & 36 & 16 & & & \\
\hline AFP (ng/ml) & & & 0.014 & 0.976 & 0.913 & $\|$ & 15 & 19 & & & \\
\hline$<300$ & 134 & 63 & & & & III & 10 & 9 & & & \\
\hline$\geq 300$ & 31 & 30 & & & & IV & 2 & 1 & & & \\
\hline NA & 35 & 41 & & & & $\mathrm{BCLC}$ & & & 0.877 & 1.112 & 0.515 \\
\hline Child-Pugh score & & & 0.082 & 1.202 & 0.581 & 0 & 2 & 2 & & & \\
\hline$A$ & 136 & 68 & & & & A & 41 & 30 & & & \\
\hline$B-C$ & 10 & 11 & & & & $\mathrm{~B}$ & 16 & 9 & & & \\
\hline NA & 56 & 55 & & & & $C$ & 4 & 4 & & & \\
\hline
\end{tabular}

Construction of the prognostic model in TCGA-LIHC

Then, "rbsurv" was used to identify seven genes to construct the risk score system. The seven genes included in the system were TTK protein kinase (TTK), chromosome 16 open reading frame 54 (C16orf54), phosphoribosyl pyrophosphate amido transferase (PPAT), CD3e molecule associated protein (CD3EAP), solute carrier organic anion transporter family member 2A1 (SLCO2A1), acetyl-CoA acetyltransferase 1 (ACAT1), and growtharrest specific 2 like 3 (GAS2L3) (Table 1).

The risk score was calculated with the following formula: risk score $=(-0.038) *$ expression of $\mathrm{TTK}+(-$ $0.357)^{*}$ expression of C16orf54 $+0.634 *$ expression of $\mathrm{PPAT}+0.221 \%$ expression of CD3EAP $+(-0.076)^{*}$ expression of SLCO2A $1+(-0.184)^{*}$ expression of ACAT1 + 0.277 *expression of GAS2L3.

In total, 334 patients were divided into two groups (134 high-risk patients and 200 low-risk patients) using a cut-off of 4.9798 for the risk score. Furthermore, the survival curve revealed that the RFS in the high-risk group was significantly poorer than that in the low-risk

(1)


A

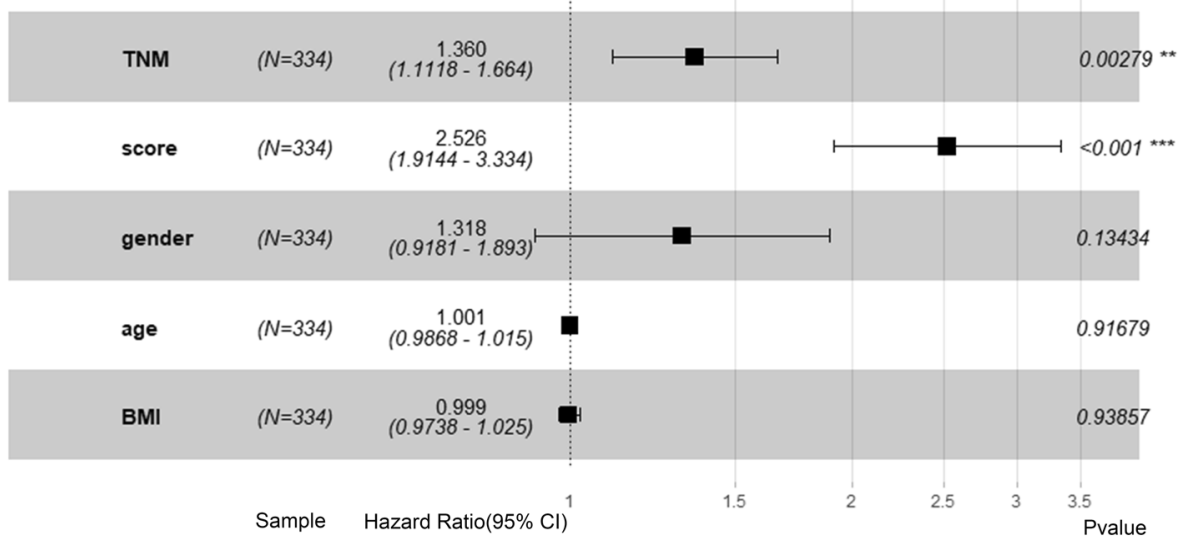

B

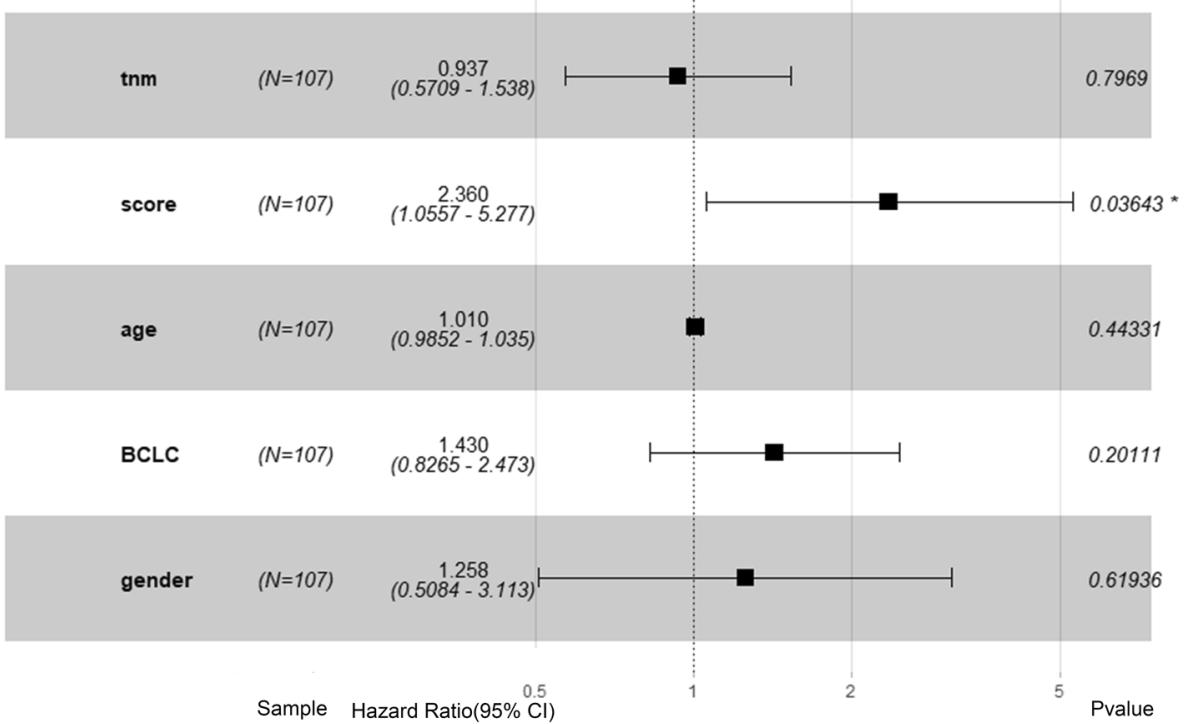

Fig. 4 Multivariate Cox regression analysis. a Multivariate Cox regression analysis of the TCGA dataset. b Multivariate Cox regression analysis of the GSE76427 dataset

cut-off of 3.4144 for the risk score. Furthermore, the survival curve revealed that the RFS in the high-risk group was significantly poorer than that in the low-risk group ( $p=0.011$; Fig. 3 ). In summary, these results indicate that the prognostic model has moderate sensitivity and specificity.

\section{Association between the prognostic model and the clinical characteristics of the patients}

While assessing the correlation between the seven-gene signature and the clinical characteristics of the HCC patients, we found that a high risk score was significantly correlated with the TNM stage $(p<0.001)$, grade $(p=0.001)$, and AFP

Table 4 Univariate and multivariate Cox regression in TCGA-LIHC hepatectomized patients

\begin{tabular}{|c|c|c|c|c|c|c|}
\hline \multirow[t]{2}{*}{ Variables } & \multicolumn{3}{|c|}{ Univariate Cox regression } & \multicolumn{3}{|c|}{ Multivariate Cox regression } \\
\hline & HR & $95 \% \mathrm{Cl}$ & $\overline{p \text { value }}$ & HR & $95 \% \mathrm{Cl}$ & $p$ value \\
\hline risk score & 2.788 & $2.174-3.574$ & $<0.001$ & 2.501 & $1.660-3.376$ & $<0.001$ \\
\hline vascular invasion & 1.509 & $1.139-2.000$ & 0.004 & 1.439 & $0.949-2.183$ & 0.087 \\
\hline hepatic virus infection status & 1.170 & $0.760-1.800$ & 0.476 & 1.050 & $0.625-1.765$ & 0.854 \\
\hline
\end{tabular}


$(p=0.014)$, but was not significantly associated with the gender, age, BMI, or Child-Pugh score of the patients with HCC (Table 2). In GSE76427, the results showed that the 7-gene signature was not significantly associated with gender, age, BCLC (Barcelona Clinic Liver Cancer) or the TNM stage (Table 3).

Independent prognostic role of the prognostic gene signature Moreover, the results of the multivariate Cox regression analysis showed that the TNM stage
$(\mathrm{HR}=1.680, p<0.001)$ and our prognostic model $(\mathrm{HR}=3.607, p<0.001)$ were both independent factors of RFS among the 334 TCGA-LIHC patients. However, among the 108 patients in the GSE76427 cohort, the TNM stage was not an independent prognostic factor for RFS [24]. The prognostic model $(\mathrm{HR}=2.407, \quad p=0.014)$ was also an independent factor for RFS (Fig. 4). In addition, we performed univariate and multivariate Cox regression with other well-known pathological factors such as vascular

A

ROC at time $\mathrm{t}=360, \mathrm{AUC}=77.7$

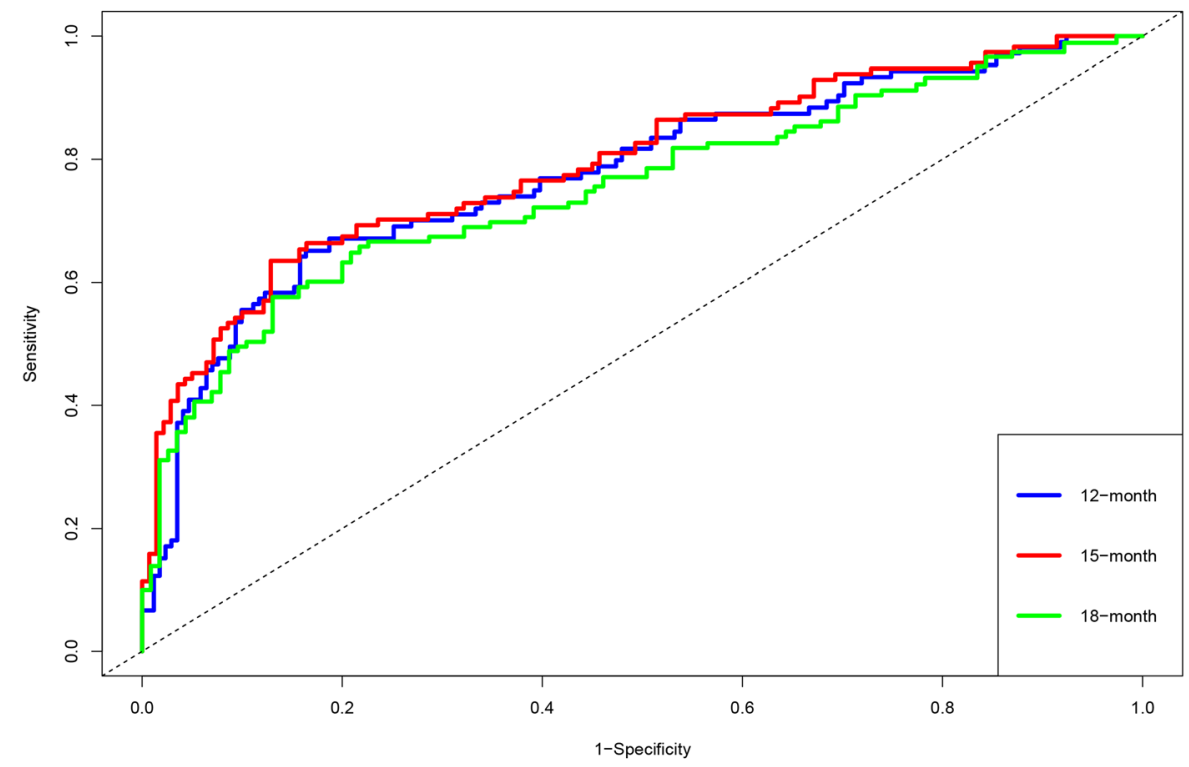

B

ROC at time $t=360, A \cup C=68.8$

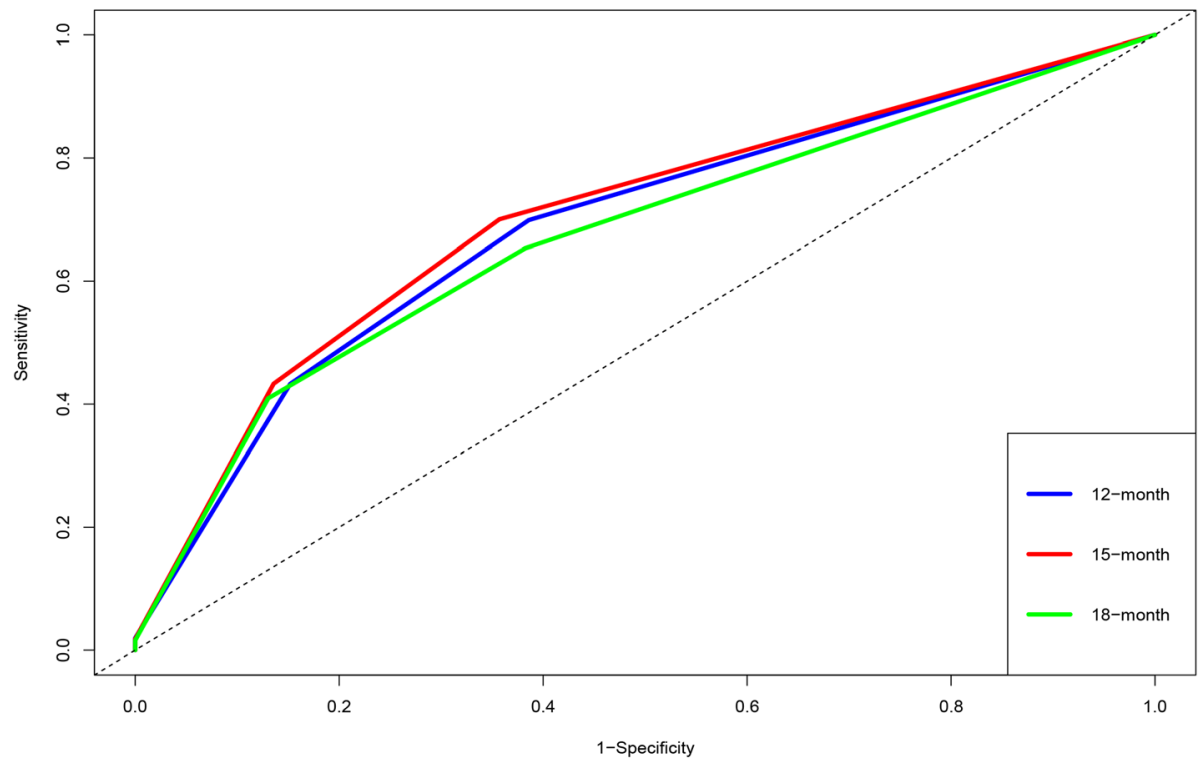

Fig. 5 Validation of the risk score predicting RFS for HCC patients in TCGA-LIHC dataset. a The prognostic model's AUCS of the 12-, 15-, and 18month RFS in the TCGA-LIHC dataset. $\mathbf{b}$ The TNM stage model's AUCS of the 12-, 15-, and 18-month RFS in the TCGA-LIHC dataset 
invasion and hepatic virus infection status in TCGALIHC hepatectomized patients. The results prove that our prognostic model is an independent prognostic factor as well (Table 4).

\section{Comparison of the TNM stage model and BCLC model}

To compare the accuracy of the prognostic model and the TNM model, we calculated the AUCs of the 12-month, 15-month, and 18-month RFS. In the TCGA-LIHC dataset, the prognostic model's AUCs of the 12-month, 15-month, and 18-month RFS were $0.7768,0.7934$, and 0.7529 , and the TNM model's AUCs of the 12-month, 15-month, and 18-month RFS were $0.6884,0.7026$, and 0.6721 , respectively (Fig. 5). In the GSE76427 dataset, the prognostic model's AUCs of the 12-month, 15-month, and 18-month RFS were $0.6159,0.6118$, and 0.6217 , and the TNM model's AUCs of the 12-month, 15-month, and 18month RFS were 0.6122, 0.6009, and 0.5762, respectively. In addition, the BCLC model's AUCs of the 12-month, 15-month, and 18-month RFS were $0.5669,0.5627$, and 0.5684 , respectively (Table 5). Overall, our prognostic model showed a benefit in predicting the RFS, which might help doctors with targeted treatment (Fig. 6).

\section{Development of the calibration curve}

We calculated the $\mathrm{C}$-index and drew calibration curves for the 12-, 15- and 18-month survival predictions to evaluate the calibration in the TCGA-LIHC dataset and the GSE76427 dataset. The C-index of the TCGA-LIHC dataset and GSE76427 dataset was 0.717 and 0.647 , respectively, as shown in Figs. 7 and 8.

\section{External validation in an online database}

The representative protein expression levels of SLCO2A1, PPAT, GAS2L3, CD3EAP, and ACAT1 were explored in the Human Protein Profiles. Then, we explored the TTK, C16orf54, PPAT, CD3EAP, SLCO2A1, ACAT1, and GAS2L3 genes in the CBioPortal for cancer genomics. TTK exhibited the most frequent genetic alterations (3\%), and deep deletion was the most frequent alteration. The second most altered gene was CD3EAP $(1.3 \%)$, and the most frequent alterations were amplification mutations (Fig. 9). The expression levels of the seven genes in different cancers are shown in Fig. 10. In summary, the aberrant expression of these seven genes may explain some of the abnormal expression of these genes.

\section{Discussion}

In this study, we developed a risk score based on seven genes that has the ability to predict the probability of RFS in HCC patients and is more accurate than clinical indicators. Using this model, we can identify patients with HCC who have a higher risk of recurrence, indicating that these patients need more attention. In the TCGA-LIHC dataset, in total, 1331 genes were found to be associated with RFS in HCC patients. In the KEGG analysis, we found that the 1331 genes were enriched in signaling pathways, such as the cell cycle, homologous recombination, DNA replication, the Fanconi anemia pathway, complement and coagulation cascades, and the $\mathrm{T}$ cell receptor signaling pathway. This finding suggests that the 7-gene signature might affect the RFS of HCC patients through these pathways. Then, we selected the best 7 genes to develop the risk score model as follows: TTK, C16orf105, PPAT, CD3EAP, SLCO2A1, ACAT1, and GAS2L3. Additionally, our study showed that the TNM staging system is not an accurate indicator for the prediction of RFS in HCC patients, which is consistent with the results of other studies. According to the prognostic model, we divided the patients into low- and high-risk groups, which exhibited significant differences in RFS. This result indicated that the prognostic model could be used as a conventional tool for the prediction of the RFS of HCC patients.

Table 5 Comparison of the prognostic model with the TNM and BCLC model

\begin{tabular}{|c|c|c|c|}
\hline Model & TNM model & BCLC model & Prognostic model \\
\hline \multicolumn{4}{|l|}{ TCGA-LIHC } \\
\hline 12-month AUC & $0.6884(0.6272-0.7496)$ & & $0.7768(0.7180-0.8356)$ \\
\hline 15-month AUC & $0.7026(0.6416-0.7636)$ & & $0.7934(0.7367-0.8501)$ \\
\hline 18-mouth AUC & $0.6721(0.6086-07356)$ & & $0.7529(0.6905-0.8153)$ \\
\hline \multicolumn{4}{|l|}{ GSE76427 } \\
\hline 12-month AUC & $0.6122(0.4733-0.7511)$ & $0.5669(0.4408-0.6931)$ & $0.6159(0.4596-0.7722)$ \\
\hline 15-month AUC & $0.6009(0.4692-0.7326)$ & $0.5627(0.4400-0.6853)$ & $0.6118(0.4679-0.7575)$ \\
\hline 18-mouth AUC & $0.5762(0.4453-0.7072)$ & $0.5684(0.4458-0.6910)$ & $0.6217(0.4828-0.7605)$ \\
\hline
\end{tabular}



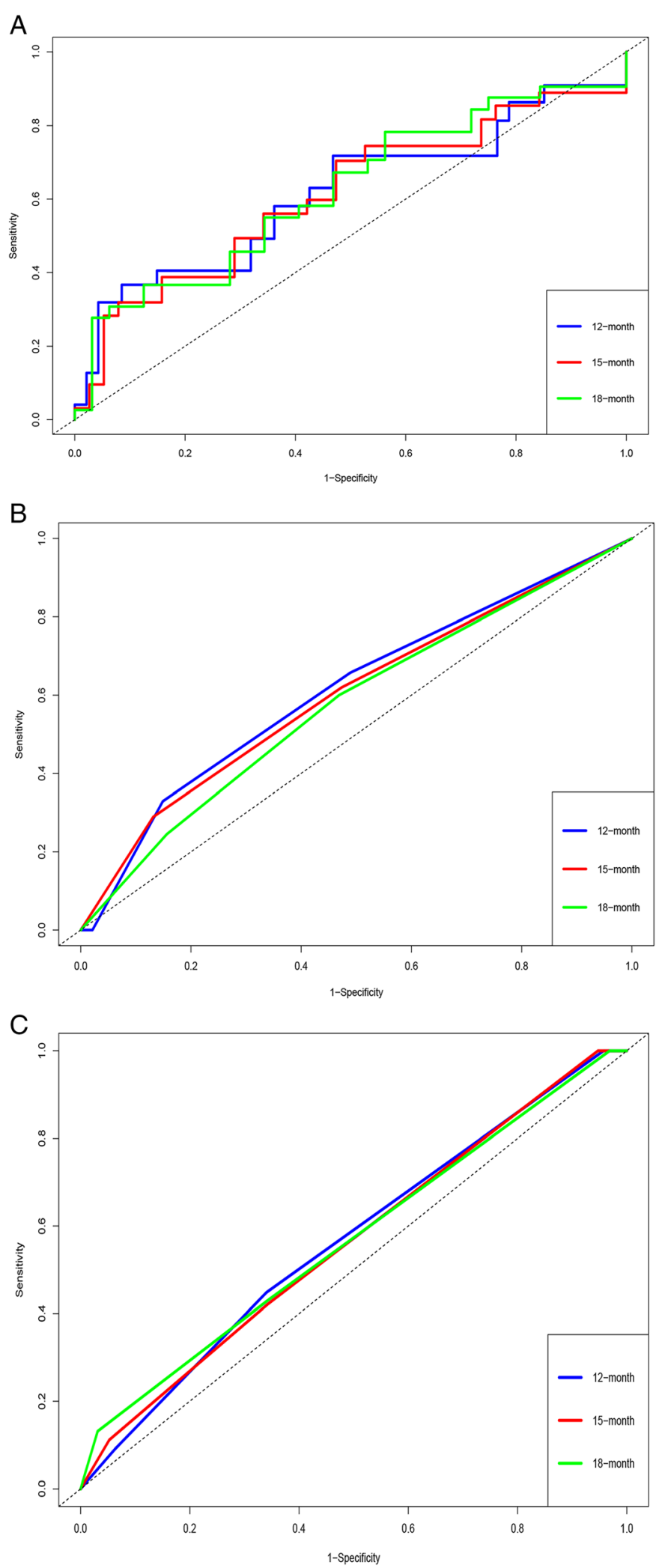

Fig. 6 Validation of the risk score predicting RFS for HCC patients in GSE76427 dataset. a The prognostic model's AUCS of the 12-, 15-, and 18month RFS in the GSE76427 dataset. b The TNM stage model's AUCs of the 12-, 15-, and 18-month RFS in the GSE76427 dataset. c The BCLC model's AUCS of the 12-, 15-, and 18-month RFS in the GSE76427 dataset 

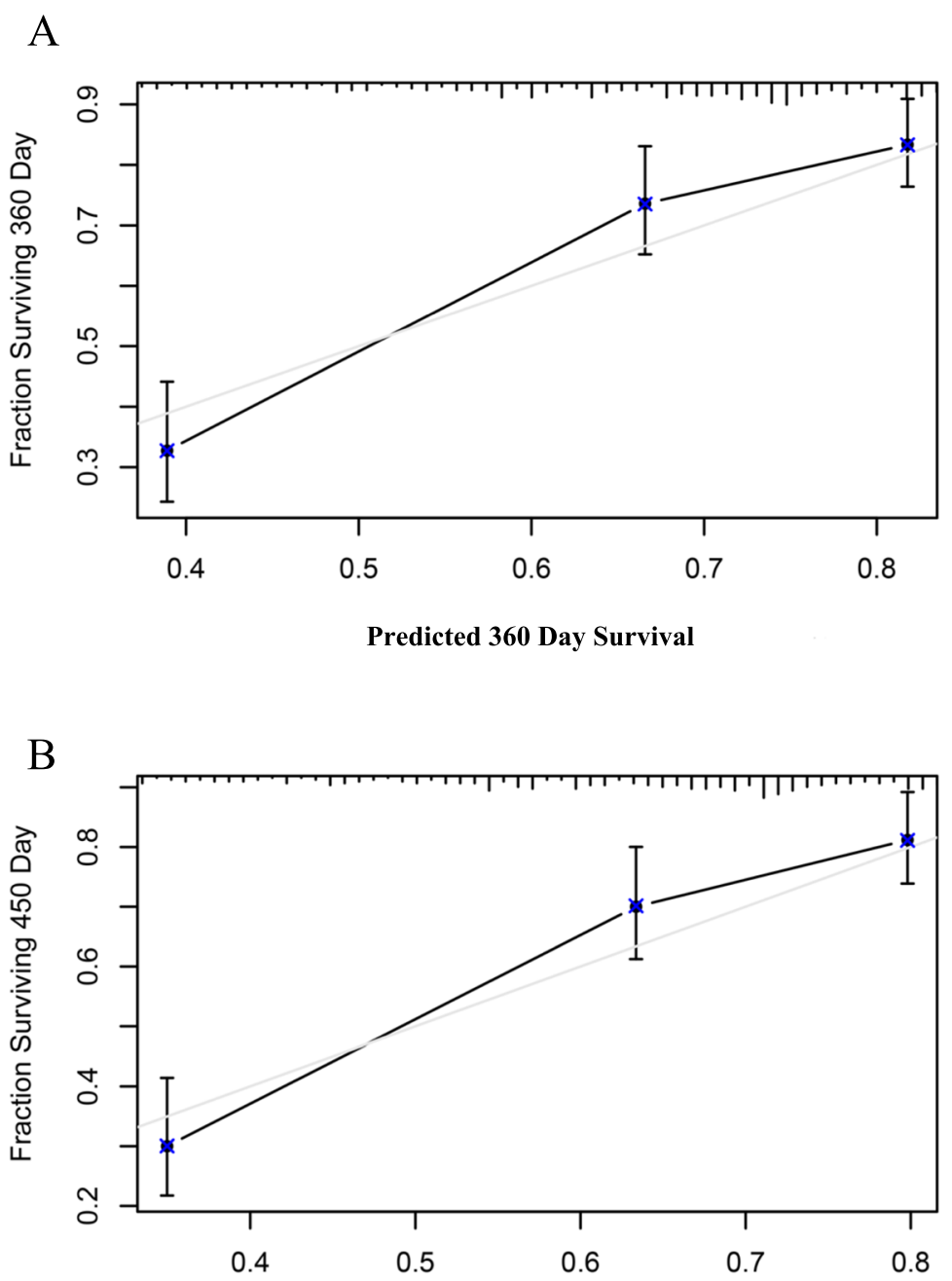

Predicted 450 Day Survival

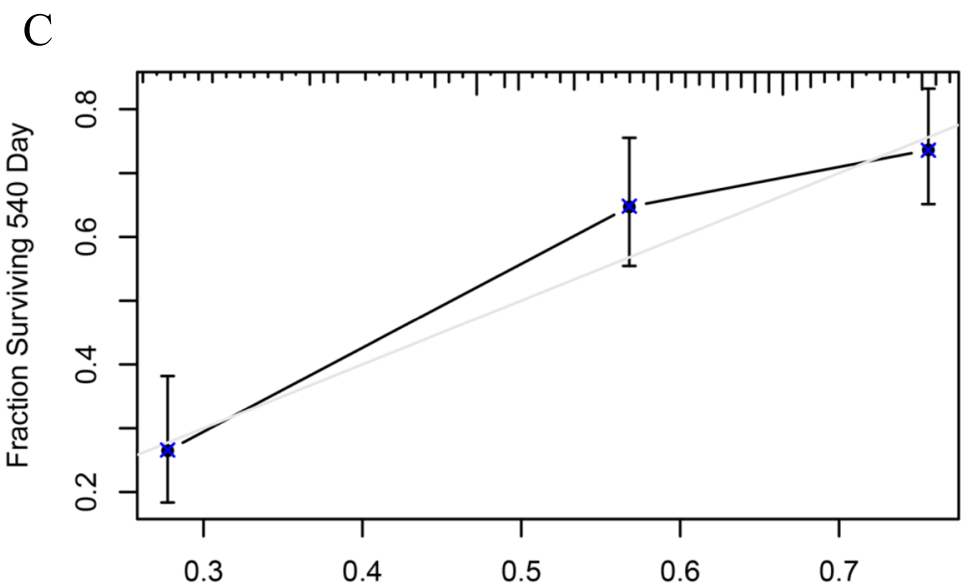

Predicted 540 Day Survival

Fig. 7 Calibration curve for the 12-month, 15-month, and 18-month periods in the TCGA-LIHC dataset. a The prognostic model was used to generate a calibration curve for the 12-month RFS prediction. b The prognostic model was used to generate a calibration curve for the 15-month RFS prediction. c The prognostic model was used to generate a calibration curve for the 18-month RFS prediction 


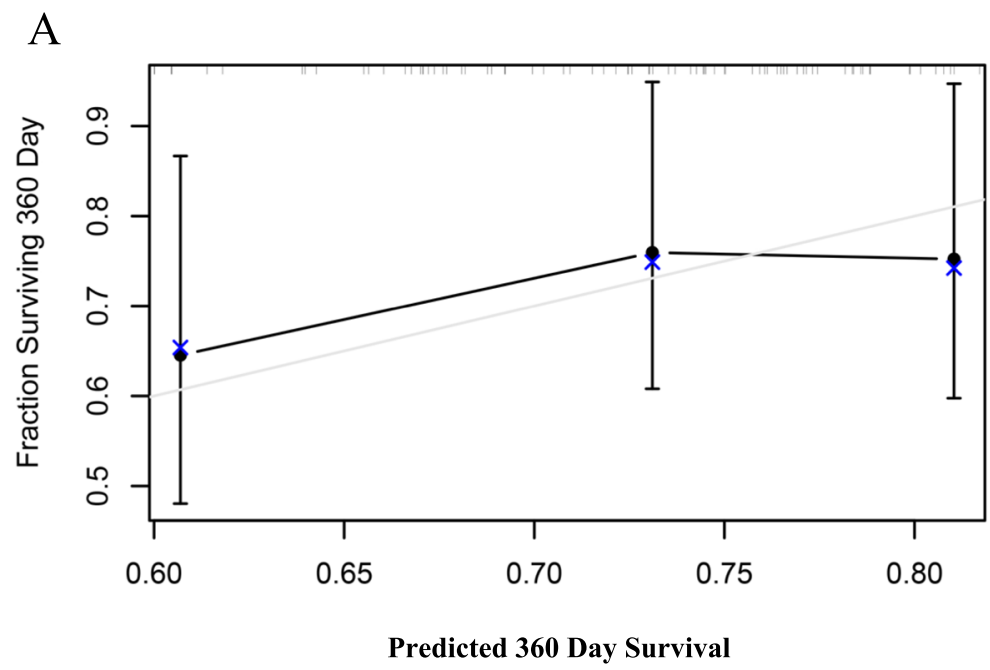

B

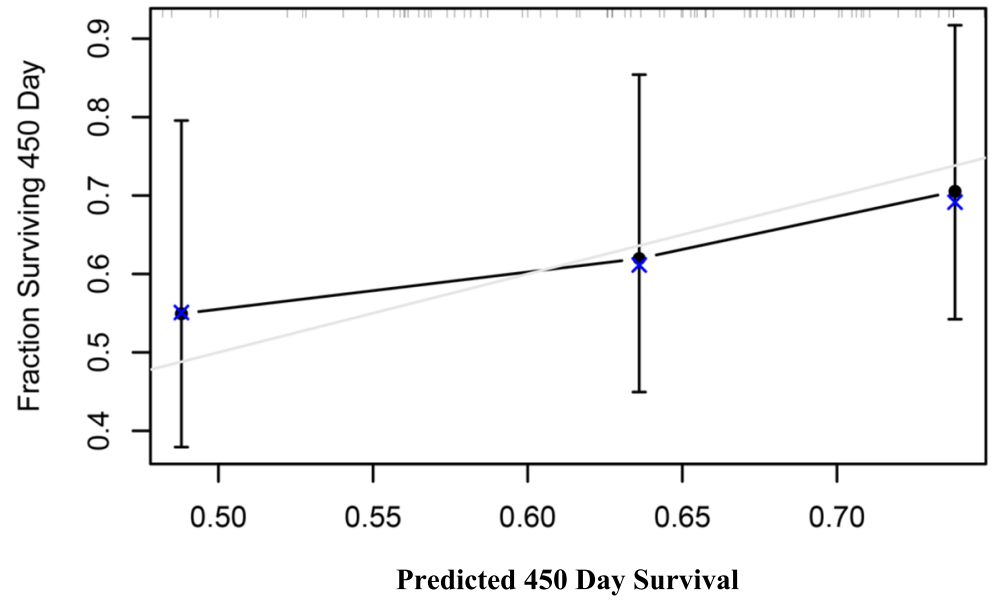

C

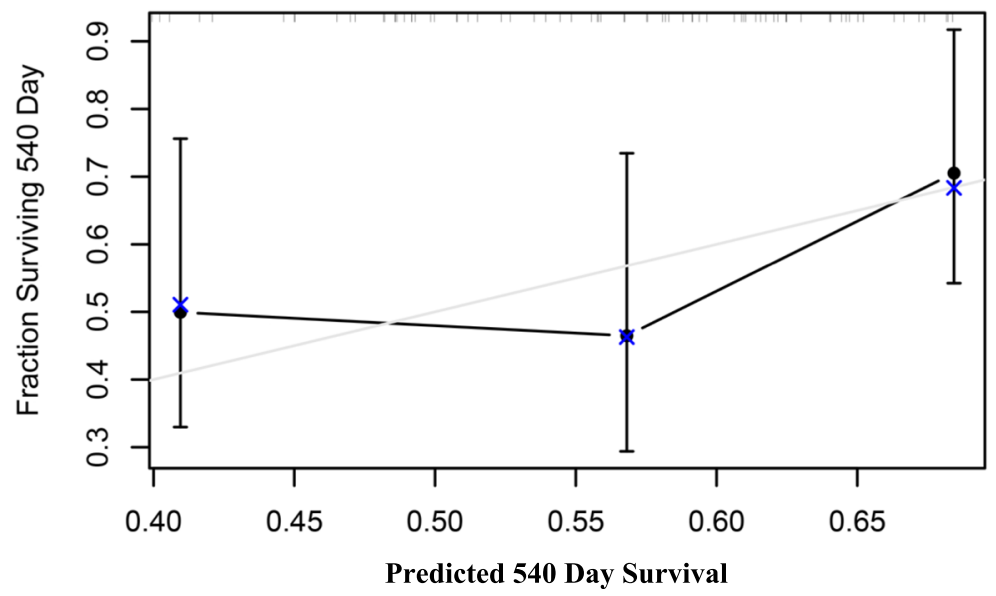

Fig. 8 Calibration curve for the 12-month, 15-month, and 18-month periods in the GSE76427 dataset. a The prognostic model was used to generate a calibration curve for the 12-month RFS prediction. $\mathbf{b}$ The prognostic model was used to generate a calibration curve for the 15-month RFS prediction. c The prognostic model was used to generate a calibration curve for the 18-month RFS prediction 


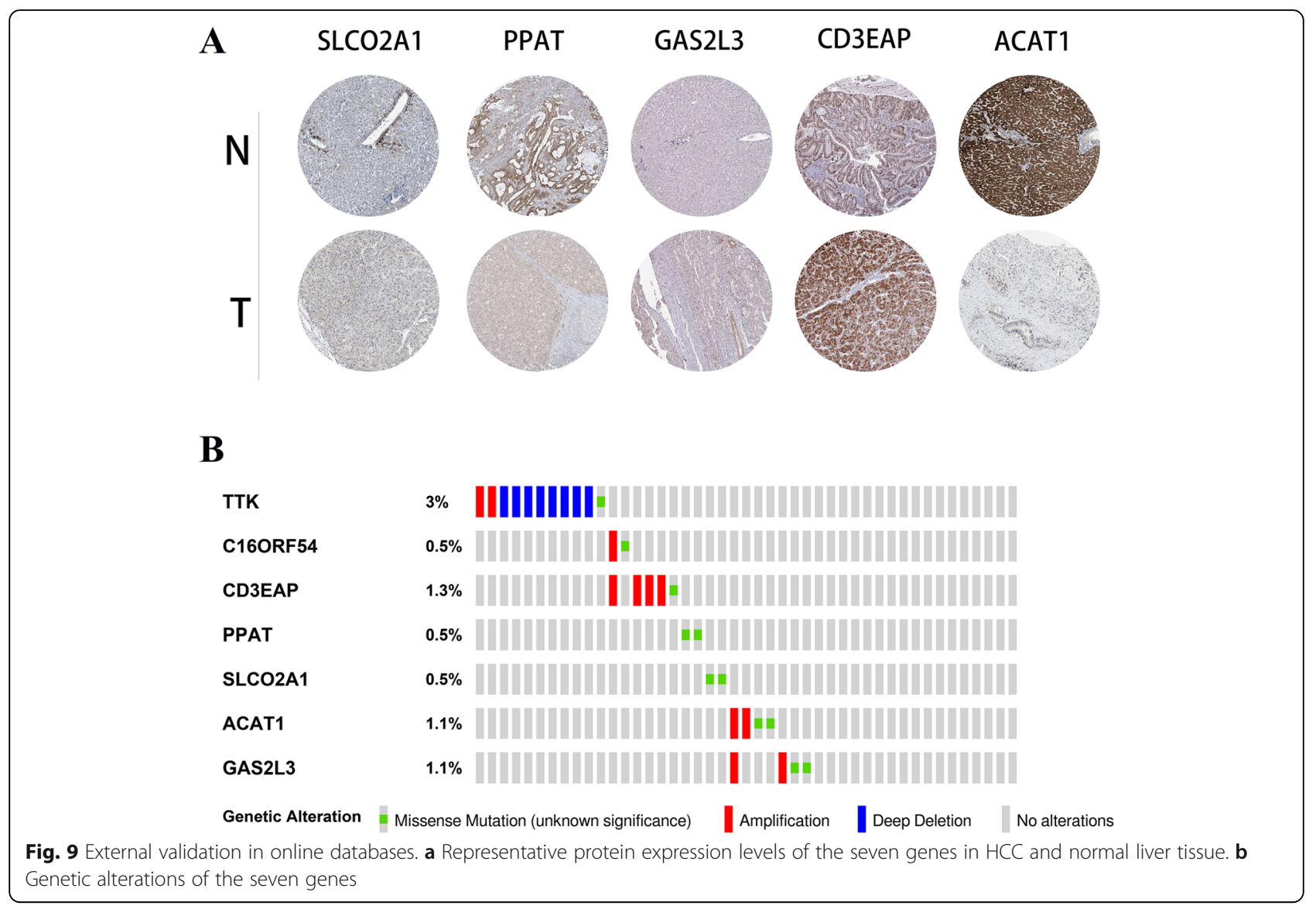

The prognostic model was validated using another independent dataset, i.e., GSE76427. The area under the curve revealed the ability of the prognostic model to differentiate the patients' prognoses; the survival curve represents the survival of the high-risk group, which had a worse prognosis compared with that of the low-risk group. These findings demonstrate that the prognostic model has the ability to forecast RFS in HCC patients.

Most of the seven genes in our prognostic model have been reported to be involved in cancer. The TTK protein levels differ in human liver cancer between liver cancer cells and adjacent noncancerous liver cells [25]. This study also tested the utility of TTK-targeted inhibition and demonstrated its therapeutic potential in an experimental model of liver cancer in vivo. Furthermore, our study demonstrated its effectiveness and incorporated it into the prognostic model. PPAT, which a member of the purine/pyrimidine phosphoribosyl transferase family, regulates pyruvate kinase activity and cell proliferation and invasion and is a biomarker of lung adenocarcinoma. Acetyl-CoA acetyltransferase (ACAT) was recently reported to be elevated in human cancer cell lines [16]. ACAT1 exhibits acetyltransferase activity and can acetylate pyruvate dehydrogenase (PDH), which affects tumor growth [26].

In other scholars' prognostic analysis of HCC, CD3EAP is also a predictor, suggesting that CD3EAP is an important predictor of $\mathrm{HCC}$ prognosis, but the function of CD3EAP is not completely clear [27]. The function of GAS2L3 is still unknown, and GAS2L3 may be involved in mediating the absorption and clearance of prostaglandins, but its function in liver cancer has not been reported [19]. Moreover, SLCO2A1 and C16orf105 have not been reported in previous $\mathrm{HCC}$ studies, indicating that these genes may be potential factors in the treatment of HCC. Understanding the function of these genes may promote the development of HCC treatment.

However, despite the potential substantial clinical significance of our results, this study still has some limitations. One limitation is that although the calibration curve performance and AUC value were excellent in the validation group, multicenter clinical application is needed to further evaluate the external utility of the prognostic model [28]. Second, only 1331 genes were defined as genes associated with RFS and evaluated for the prognostic model construction. Some important genes could have been 

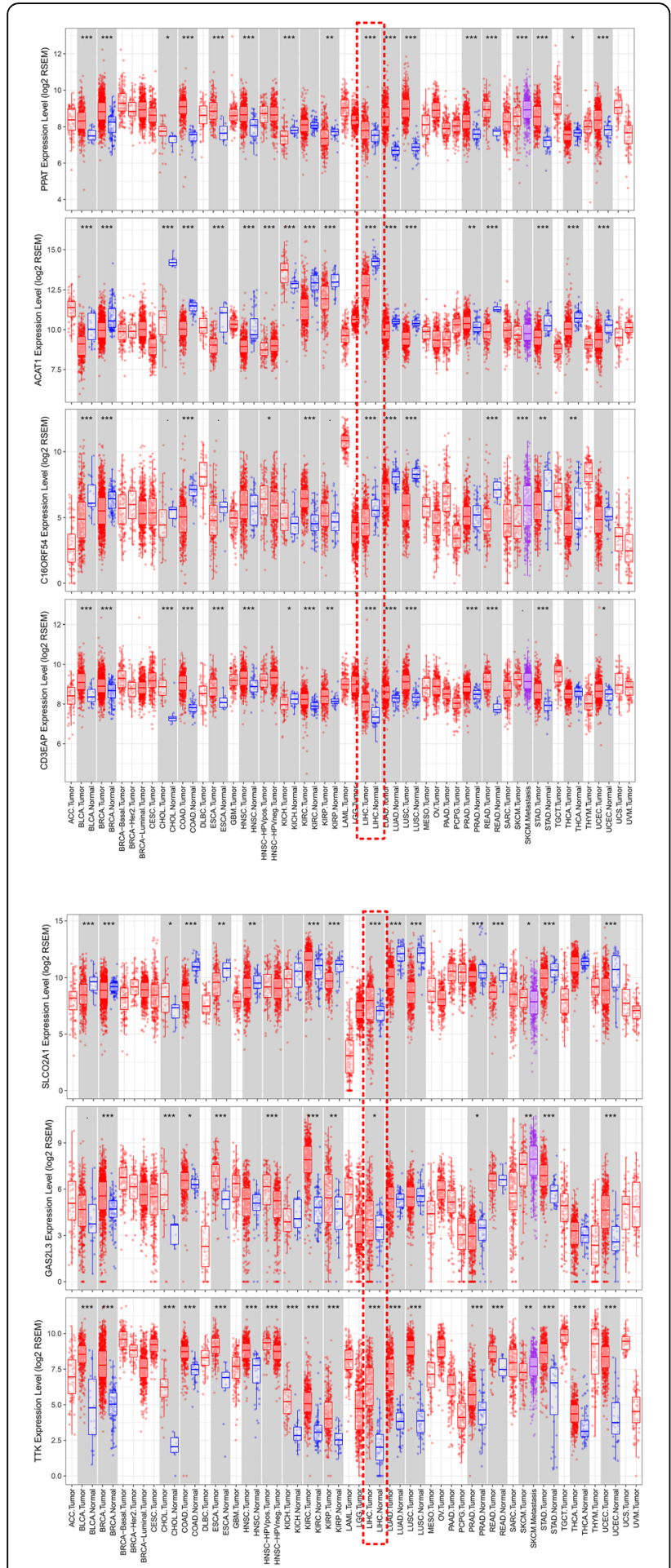

Fig. 10 Expression levels of the seven genes in different cancers

excluded before building the prognostic model [29]. In addition, knowledge regarding signaling pathways is urgently needed to reveal the functions of these genes in HCC. Finally, other well-known pathological factors, such as vascular invasion and hepatic virus infection status, should be key topics of our further studies. After collecting clinical tumor tissues with pathological information, we will find a way to combine our risk score with these clinical characteristics. Meanwhile, we have realized that many studies showed that different surgical methods had an impact on the prognosis of HCC patients. We will pay attention to distinguishing surgical methods when collecting clinical cases and compare the difference in the predictive effect of risk score on RFS in patients receiving different surgical methods in our future study.

\section{Conclusions}

In conclusion, we developed and validated a prognostic model for the prediction of the RFS probability of HCC patients. The simple prognostic model has the ability to predict RFS and could be a useful tool for doctors conducting an evaluation of $\mathrm{HCC}$ and selecting treatment plans for HCC patients.

\section{Abbreviations}

HCC: Hepatocellular carcinoma; RFS: Recurrence-free survival; TCGA: The Cancer Genome Atlas; GEO: The intergovernmental Gene Expression Omnibus; ROC: Receiver Operating Characteristic curve; TNM: Tumor Node Metastasis; BCLC: Barcelona Clinic Liver Cancer; TCGA-LIHC: The Cancer Genome Atlas-liver hepatocellular carcinoma; GO: Gene Ontology; KEGG: Kyoto Encyclopedia of Genes and Genomes; C-index: Concordance index; AUC: Area Under Curve; BMI: Body mass index; AFP: alpha fetoprotein; HR: Hazard Ratio; NA: Not available

\section{Acknowledgements}

The authors would like to thank all patients and staff who have participated in and contributed to the TCGA-LIHC registry.

\section{Authors' contributions}

WW, LW, YY, XX, YL and QL conceived and designed the study. WW, YL and $Q L$ analyzed the data. $X X, Y Y$ and $Y L$ performed the literature search. $W W$, LW, and YY wrote the paper, LW, XX and YL created the Figs. QL reviewed and edited the manuscript. All authors read and approved the final manuscript.

\section{Funding}

This research was partially supported by a grant from the National Natural Science Foundation of China (91180525 to QL). The funder is also the corresponding author, participated in the design of this research, and edited the manuscript.

\section{Availability of data and materials}

The gene expression profiles and clinical information datasets downloaded from The Cancer Genome Atlas (TCGA-LIHC)(https://portal.gdc.cancer.gov) and the Gene Expression Omnibus (GEO)(https://www.ncbi.nlm.nih.gov), accession numbers: GSE76427. Genetic alterations was retrieved from the cBioPortal website (http://www.cbioportal.org/).

\section{Ethics approval and consent to participate}

No permissions were required to use any of the repository data as all TCGALIHC data and GSE76427 date were publicly available.

Consent for publication

Not applicable.

\section{Competing interests}

The authors have no competing interests to declare. 


\section{Author details}

'Jiangxi Provincial Key Laboratory of Preventive Medicine, Nanchang University, Nanchang 330006, Jiangxi, China. ${ }^{2}$ Department of Biostatistics and Epidemiology, School of Public Health, Nanchang University, Nanchang 330006, Jiangxi, China. ${ }^{3}$ Center for Experimental Medicine, The First Affiliated Hospital of Nanchang University, Nanchang 330006, Jiangxi, China. ${ }^{4}$ Department of General Surgery, The First Affiliated Hospital of Nanchang University, Nanchang 330006, Jiangxi, China.

Received: 20 May 2020 Accepted: 25 November 2020

Published online: 05 January 2021

\section{References}

1. Siegel RL, Miller KD, Jemal A. Cancer statistics, 2019. CA Cancer J Clin. 2019; 69(1):7-34.

2. Torre LA, Bray F, Siegel RL, Ferlay J, Lortet-Tieulent J, Jemal A. Global cancer statistics, 2012. CA Cancer J Clin. 2015;65(2):87-108.

3. Li G, Xu W, Zhang L, Liu T, Jin G, Song J, et al. Development and validation of a CIMP-associated prognostic model for hepatocellular carcinoma. EBioMedicine. 2019;47:128-41.

4. Facciorusso A, Serviddio G, Muscatiello N. Transarterial radioembolization vs chemoembolization for hepatocarcinoma patients: a systematic review and meta-analysis. World J Hepatol. 2016;8(18):770-8.

5. Rognoni C, Ciani O, Sommariva S, Facciorusso A, Tarricone R, Bhoori S, et al. Trans-arterial radioembolization in intermediate-advanced hepatocellular carcinoma: systematic review and meta-analyses. Oncotarget. 2016;7(44): 72343-55.

6. Chun YH, Kim SU, Park JY, Kim DY, Han KH, Chon CY, et al. Prognostic value of the 7th edition of the AJCC staging system as a clinical staging system in patients with hepatocellular carcinoma. Eur J Cancer. 2011;47(17):2568-75.

7. Facciorusso A. The influence of diabetes in the pathogenesis and the clinical course of hepatocellular carcinoma: recent findings and new perspectives. Curr Diabetes Rev. 2013;9(5):382-6.

8. Facciorusso A. Drug-eluting beads transarterial chemoembolization for hepatocellular carcinoma: current state of the art. World J Gastroenterol. 2018;24(2):161-9.

9. Cabral LKD, Tiribelli C, Sukowati CHC. Sorafenib resistance in hepatocellular carcinoma: the relevance of genetic heterogeneity. Cancers. 2020;12(6):1576.

10. Gu JX, Zhang X, Miao RC, Xiang XH, Fu YN, Zhang JY, et al. Six-long noncoding RNA signature predicts recurrence-free survival in hepatocellular carcinoma. World J Gastroenterol. 2019;25(2):220-32.

11. Amin MB, Greene FL, Edge SB, Compton CC, Gershenwald JE, Brookland RK, et al. The eighth edition AJCC cancer staging manual: continuing to build a bridge from a population-based to a more "personalized" approach to cancer staging. CA Cancer J Clin. 2017;67(2):93-9.

12. Liao X, Yang C, Huang R, Han C, Yu T, Huang K, et al. Identification of potential prognostic long non-coding RNA biomarkers for predicting survival in patients with hepatocellular carcinoma. Cell Physiol Biochem. 2018;48(5):1854-69.

13. Gao Z, Zhang D, Duan $Y$, Yan L, Fan $Y$, Fang Z, et al. A five-gene signature predicts overall survival of patients with papillary renal cell carcinoma. PLoS One. 2019;14(3):e0211491.

14. Chen SH, Wan QS, Zhou D, Wang T, Hu J, He YT, et al. A simple-to-use Nomogram for predicting the survival of early hepatocellular carcinoma patients. Front Oncol. 2019;9:584.

15. Yuan SX, Yang F, Yang Y, Tao QF, Zhang J, Huang G, et al. Long noncoding RNA associated with microvascular invasion in hepatocellular carcinoma promotes angiogenesis and serves as a predictor for hepatocellular carcinoma patients' poor recurrence-free survival after hepatectomy. Hepatology. 2012;56(6):2231-41.

16. Goudarzi A. The recent insights into the function of ACAT1: a possible anticancer therapeutic target. Life Sci. 2019;232:116592.

17. Lee JH, Jung S, Park WS, Choe EK, Kim E, Shin R, et al. Prognostic nomogram of hypoxia-related genes predicting overall survival of colorectal cancer-analysis of TCGA database. Sci Rep. 2019;9(1):1803.

18. Joyce $\mathrm{S}$, Nour AM. Blocking transmembrane219 protein signaling inhibits autophagy and restores normal cell death. PLoS One. 2019;14(6):e0218091.

19. Wang Y, Sun L, Li Z, Gao J, Ge S, Zhang C, et al. Hepatoid adenocarcinoma of the stomach: a unique subgroup with distinct clinicopathological and molecular features. Gastric Cancer. 2019;22(6):1183-92.
20. Liu GM, Zeng HD, Zhang CY, Xu JW. Identification of a six-gene signature predicting overall survival for hepatocellular carcinoma. Cancer Cell Int. 2019;19:138

21. Wang L, Yan Z, He X, Zhang C, Yu H, Lu Q. A 5-gene prognostic nomogram predicting survival probability of glioblastoma patients. Brain Behav. 2019; 9(4):e01258.

22. Luo D, Deng B, Weng M, Luo Z, Nie X. A prognostic 4-IncRNA expression signature for lung squamous cell carcinoma. Artif Cells Nanomed Biotechnol. 2018;46(6):1207-14

23. Liu GM, Xie WX, Zhang CY. Identification of a four-gene metabolic signature predicting overall survival for hepatocellular carcinoma. J Cell Physiology. 2019;235(2):1624-1636.

24. Buti S, Karakiewicz PI, Bersanelli M, Capitanio U, Tian Z, Cortellini A, et al. Validation of the GRade, age, nodes and tumor (GRANT) score within the surveillance epidemiology and end results (SEER) database: a new tool to predict survival in surgically treated renal cell carcinoma patients. Sci Rep. 2019:9(1):13218.

25. Miao R, Wu Y, Zhang H, Zhou H, Sun X, Csizmadia E, et al. Utility of the dual-specificity protein kinase TTK as a therapeutic target for intrahepatic spread of liver cancer. Sci Rep. 2016;6:33121.

26. Chen L, Peng T, Luo Y, Zhou F, Wang G, Qian K, et al. ACAT1 and metabolism-related pathways are essential for the progression of clear cell renal cell carcinoma (ccRCC), as determined by co-expression network analysis. Front Oncol. 2019;9:957.

27. Zhang G, Xue P, Cui S, Yu T, Xiao M, Zhang Q, et al. Different splicing isoforms of ERCC1 affect the expression of its overlapping genes CD3EAP and PPP1R13L, and indicate a potential application in non-small cell lung cancer treatment. Int J Oncol. 2018;52(6):2155-65.

28. Abdelnabi M, Almaghraby A, Saleh Y, Abd Elsamad S. Hepatocellular carcinoma with a direct right atrial extension in an HCV patient previously treated with direct-acting antiviral therapy: a case report. Egypt Heart J. 2019;71(1):5

29. Abou-Alfa GK, Shi Q, Knox JJ, Kaubisch A, Niedzwiecki D, Posey J, et al. Assessment of treatment with Sorafenib plus doxorubicin vs Sorafenib alone in patients with advanced hepatocellular carcinoma: phase 3 CALGB 80802 randomized clinical trial. JAMA Oncology. 2019;5(11):1582-1588

\section{Publisher's Note}

Springer Nature remains neutral with regard to jurisdictional claims in published maps and institutional affiliations.
Ready to submit your research? Choose BMC and benefit from:

- fast, convenient online submission

- thorough peer review by experienced researchers in your field

- rapid publication on acceptance

- support for research data, including large and complex data types

- gold Open Access which fosters wider collaboration and increased citations

- maximum visibility for your research: over $100 \mathrm{M}$ website views per year

At $\mathrm{BMC}$, research is always in progress.

Learn more biomedcentral.com/submissions 